\title{
Researching a segmented market: reflections on telephone interviewing
}

\author{
Lord, Rhiannon
}

Bolton, Nicola

Fleming, Scott

Anderson, Melissa

This is the author approved version of the manuscript, (c) 2016 Emerald publishing group. Publishing and permission has been granted for this version to appear at Abertay Research Collections (https://repository.abertay.ac.uk/jspui/). Emerald does not grant permission for this article to be further copied/distributed or hosted elsewhere without the express permission from Emerald Group Publishing Limited.

Available from: https://dx.doi.org/10.1108/MRR-01-2015-0020 
Telephone interviewing on lifestyles, sport, exercise and physical activity:

Methodological reflections

Rhiannon Lord

Sport \& Exercise Sciences Division

Abertay University

Dundee

UK

Nicola Bolton

Cardiff School of Sport

Cardiff Metropolitan University

Cardiff

UK

Scott Fleming

Research and Enterprise Services

Cardiff Metropolitan University

Cardiff

UK

Melissa Anderson

Cardiff School of Sport

Cardiff Metropolitan University

Cardiff

UK 


\section{Abstract:}

Purpose: The purpose of the present study was to review the effectiveness of telephone interviewing for capturing data and to consider in particular the challenges faced by telephone interviewers.

Design / methodology / approach: The platform for this methodological critique was a market segment analysis commissioned by Sport Wales which involved a series of 85 telephone interviews completed during 2010. Two focus groups involving the six interviewers involved in the study were convened in order to reflect on the researchers' experiences.

Findings: There are three principal sets of findings. First, although telephone interviewing is generally a cost-effective data collection method, it is important to consider both the actual costs (i.e., time spent planning and conducting interviews) as well as the opportunity costs (i.e., missed appointments, 'chasing participants'). Second, researchers need to be sensitised to and sensitive to the demographic characteristics of telephone interviewees (insofar as these are knowable), because responses are influenced by them. Third, the anonymity of telephone interviews may be more conducive for discussing sensitive issues than face-to-face interactions.

\section{Originality / value}

The present study adds to this modest body of literature on the implementation of telephone interviewing as a research technique. It provides valuable methodological background detail about the intricate, personal experiences of researchers undertaking this method 'at a distance' and without visual cues, and makes explicit the challenges of telephone interviewing for the purposes of data capture.

Keywords: Telephone interviews; social policy; sport; lifestyles; market segments 


\section{Introduction}

Telephone interviewing is a cost-effective way of capturing data from people over a large geographical space, particularly in comparison to other methods such as face-toface interviews (Shuy, 2002; Stephens, 2007). Existing accounts of telephone interviewing are mainly procedural in nature, forming a step-by-step 'how to' guide (e.g., Gratton \& Jones, 2004), or present a comparative analysis of telephone interviewing when considered alongside other interviewing techniques (e.g., Struges \& Hanrahan, 2004). This information provides valuable methodological background, but little has been published on the issues associated with telephone interviewing; specifically the intricate, personal experiences of researchers undertaking this method 'at a distance' and without visual cues.

The present study adds to this modest body of literature and presents reflections on qualitative, semi-structured telephone interviews conducted in 2010 with members of the public $(\mathrm{N}=85)$ about their lifestyles in relation to sport, exercise and physical activity. The research was conducted on behalf of Sport Wales as part of their Market Segmentation project (Sports Council Wales, 2008). In doing so, we seek to develop a clearer understanding of the challenges of telephone interviewing for the purposes of data capture, which in turn might aid and underpin further implementation of this method.

The discussion that follows has four sections. The first provides contextual background for the use of telephone interviewing in social policy research and includes information on the market segmentation categories that were the basis of the study. There then follows a note on process before addressing the experiential methodological reflections of the research team. Finally, there is a summary of the implications for future research practice. 


\section{Background and context}

England's national strategy for sport and physical activity, Game Plan (Department of Culture, Media and Sport [DCMS] and the Strategy Unit, 2002), concluded that: 'the use of the General Household Survey [GHS] as a source of participation data was inadequate for planning purposes' (p.113). Hitherto, policy making in sport and exercise had been based on the data yielded by the GHS, but it had become clear that this was unsatisfactory for three main reasons (Rowe, 2009). First, there was a lack of continuity in the GHS data because sport-related questions could only be included every three years. Second, the scope and content of sport-related questions included were inflexible. Third, local level data were absent. Game Plan (DCMS / Strategy Unit, 2002) identified 'a need to establish a system for collecting and collating participation data on a consistent and long term basis' (p.113). The response from Sport England, in October 2005, was to invest $£ 5$ million in establishing the largest sport and physical activity survey in Europe (Rowe 2014). Apart from 2006-07, the Active People Survey has run continuously using telephone interviews with the sample size reduced from 364,000 in 2005-06 to 177,000 from 2007 (Rowe, 2009). .

A principal focus of the Welsh Government's national strategic plan, Climbing Higher, is to raise physical activity in Wales (Welsh Assembly Government, 2005) and as in England, physical activity targets were established for adults and children. In contrast to England, however, separate biennial surveys on adult and children's participation have been undertaken since 1987. These surveys collected data face-toface and are of sufficient size to produce local authority level analyses. Working in partnership with Experian (the global information services group), Sport Wales developed market segmentation profiles (Sports Council Wales, 2008) which divide the general population into differentiated groups (Proctor, 2000). In total, twelve segments 
were created each with a given collective name (e.g., Dot, Huw, Mark, Bob \& Betty etc.). Theoretically, each individual in the adult population of Wales could be placed into one of these 12 segments based on their demographic characteristics (e.g., gender, age, income, geographical location) and lifestyle patters (e.g., health status, family circumstances, sport and physical activity patterns). Sport Wales identified certain segments where there was less certainty of the 'fit' of these segments and hence five segments were pre-selected by Sport Wales for further research: John \& Ann (a middle aged family unit), Lisa, Sian, Christine and Steve (see table 1).

[Table 1 about here]

\section{A note on process}

Following ethical approval for the study, the research process involved two phases. The first involved making contact and recruiting participants from each of the five priority segments. Once recruited, the second phase of research was to conduct individual telephone interviews. Their purpose was to 'check' whether the key elements from the market profiles 'matched' the individuals identified as exemplars of the segments concerned and also to explore further the characteristics associated with each group. Six researchers were involved with the research project either to recruit participants in phase one and / or to conduct telephone interviews in phase two. Two researchers (including the principal investigator) were involved in both phases of the research,

From the initial Wales Adult Participation Survey (2008-09) 4,000 people had agreed to participate in this follow-up research. The aim of phase one was to recruit 125 potential interviewees. A limitation of Sport Wales' research contract, however, was the timing of the expiry of their database which resulted in only five days being available to complete the recruitment task. Two major logistical challenges were encountered: first, the brief duration of the recruitment 'window'; second, some original contact 
information from the Sport Wales Adult Participation Survey which had been undertaken 18 months earlier and was already out of date.

A sampling frame of the five priority segments was created based on the population in Sport Wales' four macro research regions - the Valleys, Metropolitan Wales, Rural North and Rural Heartland (Sports Council for Wales, 2008). A target total of 150 participants with 30 from each segment allowed five extra people per segment in case of any problems with contacting them at a later date. Four researchers undertook this task, which required 'cold-calling' members of the public. In order to maximise potential take-up there were morning, afternoon and evening 'shifts' over the five days, covering both weekdays and the weekend. Contact was made with the potential participants reintroducing them to the project, and on their agreement a convenient time was booked for the telephone interview.

The second phase involved four researchers carrying out the telephone interviews with the participants. Interviews, using a semi-structured schedule, were conducted in a given 45 minute time slot (approximately 30 minutes for the interview and 15 minutes for making further notes and reflections). The intention was to provide a clear structure for the interview to maintain consistency among the researchers and across the selected market segments, but also to provide sufficient opportunity to develop conversations and areas of particular interest to the interviewees. Participants' responses to the questions were not audio recorded but were written down by the interviewers capturing as much rich data as possible (including, for example, specific television and radio programmes watched, specific brands used). If a respondent did not answer the telephone at the appointed time, the researcher would try again 10 minutes later. If there was no reply on the second attempt researchers left a message (if possible), detailing how to re-arrange the appointment (see Dicker \& Gilbert, 1988). 
Participants were offered a $£ 10$ shopping voucher as 'compensation' for their time - importantly, though, this was not used as part of the 'pitch' to secure involvement in the project in case it may have compromised the true voluntariness of the consent that had been secured. It was only made known once the participant had agreed to be interviewed, and the vouchers were the sent to each participant once the interview had been completed together with a letter of thanks.

A total of 85 interviews were completed across the five segments. A document entitled 'A Market Segment Analysis' was compiled and provided feedback on each individual giving a rich, detailed, descriptive account of people's lives (Cardiff School of Sport, 2011). The interview data were then cross-checked with the information provided by Experian and Sport Wales, providing both corroboration and contradiction within each of the segment profiles.

In order to reflect on the research project and the experience of conducting telephone interviews, two focus groups were undertaken by the researchers: one following the recruitment phase; and another following the telephone interviews. The purpose of the first focus group was to identify issues associated with the recruitment of participants; the second focus group centred on the process of undertaking the telephone interviews and the researchers' experiences of this method. The focus groups lasted 40 minutes and 50 minutes respectively. These conversations were then transcribed and thematically analysed (Maykut \& Morehouse, 1994). Extracts from the focus group transcripts are used in the discussion that follows to illuminate points made.

\section{Lessons learnt about telephone interviewing}

There were three principal sets of findings: recruiting participants; accessing participants from particular market segments; and the approach adopted by the 
researchers involved. We conclude with some reflections on the potential implications of our work for future studies.

\section{Recruiting participants}

There is evidence that the increase in unsolicited market research telephone calls to private residences has led to a diminished engagement in research that is conducted by telephone (Curtin, Presser \& Singer, 2000; Keeter, Kennedy, Dimock, Best \& Craighill, 2006). An initial challenge for academic researchers who wish to conduct telephone interviews may be to persuade the prospective interviewee that they are not sales representatives (Wishart, 2003). Hence a script was devised to aid the researchers recruitment of potential participants. It ensured that information about the project was relayed and highlighted how the person had been selected for the research (Appendix $1)$.

In addition, other techniques (even 'tactics') were used to set us apart from other kinds of callers. First, particular 'gatekeeper words' were used at the outset to make plain who we were and for whom we were working: "I used the words Sport Wales early on in the conversation, more so than the university name because it separated us from market research. This was key for me, so they did not think we were a commercial company or selling them something" (Male Researcher).

Second, we reminded prospective participants when they had undertaken the initial survey with Sport Wales and that they had agreed to participate in further research. As well as putting the study in context, the authenticity of the 'cold call' was verified. By relaying specific details the interviewees were often audibly more relaxed and seemed more likely to consider their continued involvement. Third, a professional and courteous yet friendly approach was cultivated to further separate us from market researchers and sales representatives. Rather than using the words, 'I'm not selling 
anything', we attempted to demonstrate empathy for taking the person's time, and if any negativity was detected towards taking part, we did not try to be 'pushy' to proceed with the conversation.

There were two main problems encountered during this recruitment phase. First, many wanted to conduct the interview immediately, though this was not feasible owing to the restriction placed on the expiry of the database of possible participants. Had we been able to, we would have secured a greater number of interviews, especially amongst respondents who later proved more difficult to contact. Second, recruitment phone calls were conducted over the same five day period, but from different locations. This resulted in a small number of clashes which were later rectified by either providing a different interviewer or re-arranging the time of the interview. There is merit, therefore, in conducting telephone interviews in the same location so that data can be shared instantaneously (Shuy, 2002). However, whilst immediate access to shared data may have been desirable for the management of recruiting participants, private spaces were needed for the interviews themselves. It was important, for example, to convey the (accurate) impression of anonymous data capture process, and to avoid the (mistaken) impression of a commercial enterprise based at a 'call centre'.

\section{Accessing participants from selected market segments}

When considering if telephone interviews are an appropriate method, researchers should consider the demographic make-up of the populations with whom they are trying to engage. Telephone interviews may be an appropriate method for contacting 'hard-toreach' populations (Struges \& Hanrahan, 2004), especially in comparison with face-toface interviews (Creswell, 1998; Miller, 1995; Tausig \& Freeman, 1988), but a more nuanced appreciation of the reasons why those respondents present challenges is important. The market segments in this project consisted of a diverse cross-section of 
society, and although all agreed to be contacted at a scheduled time, some clear patterns and differences emerged in their 'appointment-keeping' behaviours.

Out of a possible 30 participants recruited for each segment, only 15 interviews were completed with Lisa; 15 with Sian; 17 with Christine; 20 with Steve; and 18 with John and Ann. Generally, Lisa, Sian and Christine were more difficult to contact, and in a limited number of cases took between six and 10 attempts to complete. In contrast, Steve and John and Ann were relatively easy to contact. The characteristics of each segment (Table 1) provide context about the relative difficulty of making contact. For instance, older participants (John and Ann) were more likely to keep their appointments, often commenting that they had written their allocated day and time in a diary, just as they did when making any other commitments. In contrast, younger participants (Lisa and Sian) seemed to treat their appointments as a transient, less formal arrangement. Follow-up calls and interviews revealed that some had gone out, and others had forgotten or had other commitments. This led to a significant amount of wasted time and frustration for researchers who had allotted specific times to complete the research - including evenings and weekends.

The same generational variation was reported in the quality of the conversations with participants. John and Ann were more likely to answer questions fully and produce in-depth, rich data; interviews were also likely to last longer, sometimes for over an hour (which created other operational challenges). In contrast, many of the younger participants (Lisa and Sian) were more likely to give short answers and relied more on prompts. Moreover, as Struges and Hanrahan (2004) found in a different context, segments characterised by an interest in sport, exercise and physical activity (Steve and John and Ann) were more likely to participate in the interviews than those who did not (Lisa and Christine). 


\section{Reflections on the approach adopted}

One of the challenges facing telephone interviewers is the obvious absence of nonverbal communication during the conversation. Echoing Mehrabian's (1968) frequently cited study which emphasises the importance of body language and paralanguage for communication effectiveness, the logical corollary is that the absence of visual cues creates a barrier to a full appreciation of the interviewee and the data captured. Indeed visual cues are often relied upon by interviewers to help develop rapport and to assess the authenticity and engagement of the participant (Creswell, 1998; Stephens, 2007; Struges \& Hanrahan, 2004).

Recent advances in video communication have eased this particular challenge when respondents have access to the requisite technology and are willing to be interviewed in this significantly more intrusive way. In the Market Segmentation study, with some limited information about the location of the interviewee's home, an online postcode search can yield some local information that can aid contextual understanding about the person's surroundings and local community:

"This was very valuable information and helped me understand the person and their surroundings and circumstances. It also aided rapport significantly as I was able to engage in the conversation in a more meaningful way with the person on the end of the phone." (Male Interviewer) In spite of the difficulty of interpreting some aspects of verbal (telephone) communication without non-verbal cues, there are features of identity that are disclosed in voices - for example, gender, age, region of origin, and to some extent, socioeconomic status (Davis, Couper, Janz, Caldwell \& Resnicow, 2010; Stephens, 2007). Both interviewer and interviewee build a profile of the other based on the limited information that is available. One of the more obvious characteristics is gender (Davis 
et al., 2010), which often plays an important role in interviewing - sometimes based on some unsophisticated gender stereotypes (Davis et al., 2010; Davis \& Silver, 2003; Tourangeau, Rips \& Rasinski, 2000).

Telephone interviewers do not enter the homes or private spaces of their interviewees, but there was a sense that an unknown male voice may seem more threatening than the softer tone and higher pitch of a female one. Indeed there was even a sense that a young friendly researcher doing the 'cold calling' to arrange the follow-up might even have been subtly (and unintentionally) coercive. One interviewee indicated that her willingness to participate was in part because: "She couldn't refuse because the (female) person who had made the appointment was so lovely" (emphasis added).

This point is reinforced by Smoreda and Licoppe (2000) who reported on gendered usage of the domestic telephone and concluded that women are more likely to be better telephone communicators - in part because of the division of (Western) household labour and family roles, as well as the differences in type and number of social networks and interaction styles. Whether or not this ease of telephone communication is a gendered characteristic is unclear from the evidence of the present study, but there were variable levels of 'chattiness' amongst the research team. One (female) researcher remarked, "I love people's stories, people watching, that's the difference, I enjoy it." Other (male) researchers were less comfortable: "Chit chat with strangers isn't really [my] thing" and "I felt sleazy making small talk with young women".

The planning of the project had been undertaken with one eye on the outcome (successful completion) and another on the participants' personal circumstances. As one researcher explained: "We were reflecting their lifestyle, whereas commercial companies run on a shift pattern, we were trying to run an individual service." Like 
Wishart's (2003) telephone survey, there were attempts to accommodate participants' availability at odd times and outside of the usual working week. Both the interview schedule and the telephone appointments included 'contingency buffers' for unexpected events. The inherent flexibility this provided proved invaluable when interviews were not conducted as originally planned. Moreover, the importance of leaving a positive impression implied an ambassadorial commitment that researchers embraced. In the aspirational attempt of researchers to 'leave only footprints', members of the research team were keen to avoid the possibility of being thought exploitative data-gathering opportunists:

"I had one person who loved to talk and had loads of time, I think she was elderly and was living on her own in a fairly isolated area, and we were talking for over an hour... I felt obliged to talk to her, because she had taken time out of her day to help us. I felt obliged to chat and it was about the interview content, so I just allowed her to talk freely."

The idea of researchers generally behaving as 'carpet baggers' has been addressed by Corrigan (1979) and considered more explicitly in relation to interview techniques by Tomlinson (1997). The key point is that participants can often experience feelings of being 'used' and even 'violated' by researchers, an area addressed explicitly by TrierBieniek (2012).

Yet there were other instances when time was at a premium for the participant which required the researcher to capture the information as efficiently and speedily as possible:

"There was one lady who was willing to do the interview, but said that she had to leave to pick up her children in 20 minutes, so I felt obliged to rush through the 
questions. But it was a case of either completing the interview in 20 minutes or not at all."

On a few occasions it was apparent that interviewees were 'shoe-horning' the interviews into already busy and hectic lives - particularly when young children could be heard in the background demanding attention which often interrupted the flow of the interview (Stephens, 2007). The demands for flexibility in the conduction of the interviews were therefore important to use optimally the limited time that was available in some instances. That is to say, there was a need to exercise selectivity and judgement over the key themes and issues and how best to capture data about them.

\section{Implications for Future Practice}

Telephone interviewing is generally considered a cost-effective data collection method (Miller, 1995; Struges \& Hanrahan, 2004; Wishart, 2003). Usually less expensive than face-to-face interviews (Aquilino, 1992; Frey, 1983; Groves \& Kahn, 1979; Miller, 1995), they tend to be more expensive than postal surveys but have a greater response rate (Wishart, 2003). In calculating cost-effectiveness, it is important to address both the actual costs (i.e., time spent planning and conducting interviews) as well as the opportunity costs (i.e., missed appointments, 'chasing participants').

Although the market segments research was not explicitly about 'sensitive issues' (Lee, 1993; Renzetti \& Lee, 1993, Sieber \& Stanley, 1988), participants often shared opinions about the government, economic climate, 'green' policies and recycling in their local area - and were quite willing to do so (Greenfield, Midanik, and Rogers, 2000; Struges \& Hanrahan, 2004). Indeed for potentially sensitive matters some argue that telephone interviews might be more suitable than face-to-face interactions (Greenfield, Midanik \& Rogers, 2000; Struges \& Hanrahan, 2004, Trier Bieniek, 2012). For not only is the data captured and reported anonymously, but there is also a sense 
that participants may be aware that they are unlikely to meet in person or speak to the interviewer again - and even if they did, neither would visually recognise the other. As one interviewer commented: "People are quite revealing on the phone. There's an anonymity in disclosure through the phone. I was quite struck by some of the detail people did go into."

One particular advantage of the telephone interview is that it incorporates unique control of timing and social space for both the interviewer and the interviewee (Holt, 2010). Participants were willing (sometimes frustratingly for the researchers) to exercise the right to postpone or even cancel an interview. In this sense at least, the telephone interview empowers the interviewee to take control of the interaction and to conduct it on their terms. More prosaically, it is much easier to 'hang up' a phone than to walk away from a face-to-face encounter.

The variation in response rates and attitudes towards being interviewed amongst the different market segments highlights some implications for the future practice of researchers conducting telephone interviews. For consumer-led organisations, it is clear that not only are bespoke communication messages desirable, but the medium of their delivery is an important consideration for ensuring effectiveness. In turn, this presents a challenge to researchers (perhaps academic more than commercial) for whom 'reliability' and replicability are pressing priorities; and when the research is conducted by teams of researchers, the challenge is even greater. Indeed, in terms of answering the initial research questions, it may be that a repertoire of data capture methods is necessary to engage most effectively with the variety of participant types. That is to say, customised research interventions suited to the types of participants may be the most fruitful. 
For studies that are designed quite deliberately to seek the views and opinions of a wide spectrum of the general public, a differentiated approach to communication with potential participants may be the most effective. This may mean, for example, telephone interviews with one constituency and face-to-face interviews with another (see Irvine, Drew and Sainsbury, 2013). It also seems likely that a mixed method design would yield a richer and more nuanced data set and hence greater benefit not only to the researchers themselves, but also to policy shapers and practitioners.

Telephone interviews have found favour as a data capture method for attempting to measure physical activity rates in England, and have continued to gather momentum. The well-established Active People Survey, the largest of its kind in Europe, was extended in 2012 to include young people aged 14 and 15. Data derived from it are used extensively by Sport England and national government to provide evidence for setting policy (Rowe, 2009, 2014). As part of its overall strategy, Sport England has commissioned National Governing Bodies to deliver participation targets, and the Active People Survey provides the evidence to show whether or not those targets have been met. Where participation levels show sustained decline, funding is withdrawn. The need for robust data to inform evidence-based policy making is therefore significant. It also extends beyond sport and physical activity into other public policy domains. The corollary of this is that data capture methods must be fit for purpose. The present study has shown that telephone interviews may be highly appropriate for many segments of the population, but less so for others. It remains, therefore, a method that requires sensitivity to context and participant type. 


\section{Acknowledgments:}

This article is based on research commissioned by Sport Wales. The authors are grateful to Mike Wall, Becky James and Andy Miles for their work in phase one of the project, and acknowledge formally the co-operation of participants involved in that study.

\section{References}

Aquilino, W.S. (1992), “Telephone versus face-to-face interviewing for household drug use surveys", International Journal of the Addictions, Vol. 27 No. 1, pp. 71-91.

Cardiff School of Sport (2011) Market segments analysis, prepared for Sport Wales. Cardiff: Cardiff School of Sport, Cardiff Metropolitan University

Corrigan, P. (1979), Schooling the Smash Street kids, Macmillan Education, London.

Creswell, J.W. (1998), Qualitative Inquiry and Research Design: Choosing Among Five Traditions, Sage, Thousand Oaks, CA.

Curtin, R., Presser, S., and Singer, E. (2000), “The effects of response rate changes on the index of consumer sentiment”, Public Opinion Quarterly, Vol. 64 No. 4, pp. 413-428.

Davis, R.E., Couper, M.P., Janz, N. K., Caldwell, C. H and Resnicow, K. (2010), "Interviewer effects in public health surveys", Health Education Research, Vol. 25 No. 1, pp. 14-26.

Davis, D.W. and Silver, B.D. (2003), "Stereotype threat and race of interviewer effects in a survey on political knowledge", American Journal of Political Science, Vol. 47, pp. 33-45. 
Department for Culture Media and Sport and Strategy Unit (2002), Game Plan: A strategy for delivering government's sport and physical objectives, DCMS, London.

Dicker, R. and Gilbert, J. (1988), “The role of the telephone in educational research", British Educational Research Journal, Vol. 14 No. 1, pp. 65-72.

Irvine, A., Drew, P. and Sainsbury, R. (2012) 'Am I not answering your questions properly?' Clarification, adequacy and responsiveness in semi-structured telephone and face-to-face interviews. Qualitative Research, 13(1) 87-106.

Frey, J.H. (1983), Survey Research by Telephone, Sage, Beverly Hills, CA.

Gratton, C. and Jones, I. (2004), Research Methods for Sports Studies, Routledge, London.

Greenfield, T.K., Midanik, L.T. and Rogers, J.D. (2000), "Effects of telephone versus face-to-face interview modes on reports of alcohol consumption" Addiction, Vol. 95 No. 2, pp. 277-284.

Groves, R.M. and Kahn, R.L. (1979), Surveys by telephone: A national comparison with personal interviews, Academic Press: New York.

Holt, A. (2010), "Using the telephone for narrative interviewing: A research note", Qualitative Research, Vol. 10, pp. 113-121.

Irvine, A., Drew, P. and Sainsbury, R. (2012), ““Am I not answering your questions properly?' Clarification, adequacy and responsiveness in semi-structured telephone and face-to-face interviews”, Qualitative Research, Vol. 9 No 1, pp. 87106.

Keeter, S., Kennedy, C., Dimock, M., Best, J. and Craighill, P. (2006), "Gauging the impact of growing non response on estimates from a national RDD telephone survey”, Public Opinion Quarterly, Vol. 20 No. 5, pp. 759-779. 
Lee, R.M. (1993), Doing Research on Sensitive Topics, Sage, London.

Mehrabian, A. (1968), “Communication without words”, Psychology Today, September, pp. 52-55.

Maykut, P. and Morehouse, R. (1994), Beginning Qualitative Research, Falmer Press, London.

Miller, C. (1995), "In-depth interviewing by telephone: Some practical considerations", Evaluation and Research in Education, Vol. 9 No. 1, pp. 29-38.

Proctor, T. (2000), Strategic marketing: an introduction. Routledge, London.

Renzetti, C.M. and Lee, R. (1993), Eds., Researching Sensitive Topics, Sage, London.

Rowe N. F. (2009), “The Active People Survey: A catalyst for transforming evidencebased sport policy in England", International Journal of Sport Policy and Politics, Vol. 1 No. 1, pp. 89-98.

Rowe, N. F. (2014), "Sporting capital: a theoretical and empirical analysis of sport participation determinants and its application to sports development policy and practice", International Journal of Sport Policy and Politics, available at: http://www.tandfonline.com/doi/full/10.1080/19406940.2014.915228 (accessed 8 September 2014).

Shuy, R.W. (2002), "In-person versus telephone interviewing”, in Gubrium J.F. and Holstein, J.A. (Eds.), Handbook of Interview Research: Context and Method, Sage, Thousand Oaks, CA, pp. 537-555.

Sieber J.E. \& Stanley, B. (1988), "Ethical and professional dimensions of socially sensitive research", American Psychologist, Vol. 43 No. 1, pp. 49-55.

Smoreda, Z. and Licoppe, C. (2000), "Gender-specific use of the domestic telephone”, Social Psychology Quarterly, Vol. 63 No. 6, pp. 238-252.

Sports Council Wales (2008), Market segmentation. Sports Council for Wales, Cardiff. 
Sport Wales (2014),

http://www.sportwales.org.uk/media/355579/200809\%20active\%20adults\%20sur vey\%20-\%20headline\%20results, \%20by\%20local\%20authority.xls - Date accessed $15^{\text {th }}$ September 2014

Stephens, N. (2007), "Collecting data from elites and ultra elites: Telephone and faceto-face interviews with macroeconomists", Qualitative Research, Vol. 7, pp. 203216.

Struges, J.E. and Hanrahan, K.J. (2004), “Comparing telephone and face-to-face qualitative interviewing: A research note”, Qualitative Research, Vol.4, pp. 107118.

Tausig, E.W. and Freeman, J.E. (1988), “The next best thing to being there: Conducting the clinical research interview by telephone", American Journal of Orthopsychiatry, Vol. 58 No. 3, pp. 225-233.

Tomlinson, A. (1997), "Flattery and betrayal: Observations on qualitative and oral sources", in Tomlinson A. and Fleming, S. (Eds.), Ethics, Sport and Leisure: Crises and Critiques, Meyer and Meyer, Aachen, pp. 245-264.

Tourangeau, R., Rips, L.J. and Rasinski, K. (2000), The Psychology of Survey Response, Cambridge University Press, New York.

Trier-Bieniek, A. (2012), "Framing the telephone interview as a participant-centred tool for qualitative research: a methodological discussion", Qualitative Research, Vol. 12 No.6, pp. 630-644.

Wales Adult Participation Survey (2008-09) http://www.sportwales.org.uk/research--policy/surveys-and-

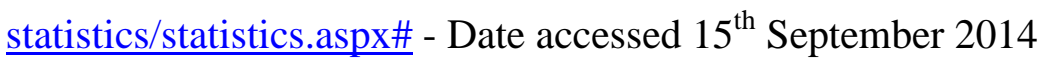


Welsh Assembly Government (2005), Climbing Higher, Welsh Assembly Government, Cardiff.

Wishart, J. (2003), "Interviewing teachers by telephone", Research in Education, Vol. 70, pp. $74-84$. 


\title{
Appendix 1: Telephone interview participant introduction
}

\author{
Hi / Hello .....
}

It's ........... from the Cardiff School of Sport. We've got an appointment to talk now, I think. Is it still convenient?

[If no] ... OK, sorry to disturb you. Can we rearrange the appointment? [Then rearrange it.]

[If yes] ... Great. Let me just remind you briefly what this is all about. We've been commissioned by the Sports Council for Wales to investigate participation in physically active leisure. There was a large survey of people across Wales in 2008, 27,000 people were involved. You were one of the 4,000 who indicated then that you'd be willing to talk to us again. The point is that surveys can only tell us so much, an interview will enable us to develop a much more precise and soophisticated understanding. So as a result of this, and 124 other telephone interviews in this phase of the work, we will write a report for the SCW, and perhaps an article for an academic journal too.

This chat will take somewhere in the region of half an hour. We're really pleased you're willing to give up your time, and as a 'thank you', we'll send you a $£ 10$ shopping voucher.

We'll talk about a few of the things that we think are important about physically active leisure, and I'll write some notes during and after the call. These won't be attributed to you (no-one will know it's you). We store the information on the data-base separately from our notes about the interview, and we comply with the Data Protection Act.

If there's any question you don't want to answer, of it you just don't want to carry on with the interview at any time, just tell me. There's no problem with either.

If you have any questions about the research or how we intend to conduct the study, you can ask me now or at the end. And afterwards if you remember something you wish you'd ask, contact the project manager, Dr Nicola Bolton. Her telephone number is 02920 416484. Or you can contact her on njbolton@uwic.ac.uk

Is all of that clear?

[If no] ... OK, let me see if I can help. What do you need to know?

[If yes] ... Great. Let me start with ... 


\begin{tabular}{|c|c|c|c|c|}
\hline Segment & Age & $\begin{array}{c}\text { \% of } \\
\text { adult } \\
\text { Welsh } \\
\text { population }\end{array}$ & Personal circumstances & Engagement in physical activity \\
\hline Christine & $36-55$ & $12.6 \%$ & $\begin{array}{l}\text { - Works part-time to supplement household income } \\
\text { - Mother to teenage children who are still financially } \\
\text { dependent } \\
\text { - Lives in traditionally working-class areas }\end{array}$ & $\begin{array}{l}\text { - Less active than national average - unlikely to be a } \\
\text { regular participant } \\
\text { Activity is likely to be walking, swimming, indoor } \\
\text { and personal fitness }\end{array}$ \\
\hline Lisa & $18-35$ & $12.5 \%$ & $\begin{array}{l}\text { - On low income or state benefits } \\
\text { - Living with a partner or raising her children as a single } \\
\text { parent in social housing } \\
\text { - Health is generally good but drinking and smoking } \\
\text { related incidences may occur } \\
\text { - Relatively high rate of pregnancy }\end{array}$ & $\begin{array}{l}\text { - Likely to participate in some physical activity - } \\
\text { usually indoor games and personal fitness, especially } \\
\text { swimming } \\
\text { - Keeping fit and fun are the main motivators for } \\
\text { participating }\end{array}$ \\
\hline Sian & $18-45$ & $7.2 \%$ & $\begin{array}{l}\text { - Shares home with a husband or partner and their } \\
\text { children } \\
\text { - Lives in a relatively affluent area surrounded by people } \\
\text { in a similar life stage } \\
\text { - Well educated and careerist }\end{array}$ & 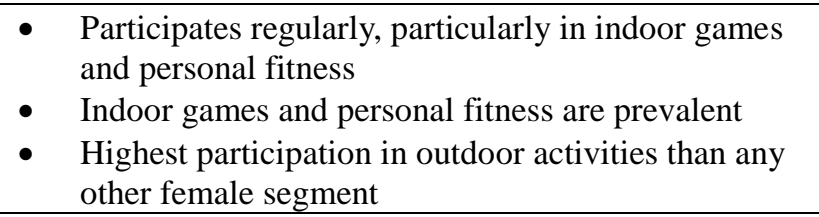 \\
\hline Steve & $26-45$ & $10.9 \%$ & $\begin{array}{l}\text { - Has a young family } \\
\text { - Likely to be in skilled 'blue-collar' work or self- } \\
\text { employed } \\
\text { - Irregular wages make if difficult to plan } \\
\end{array}$ & $\begin{array}{ll}\text { - } & \text { Participates regularly } \\
\text { - } & \text { Indoor activities most commonly undertaken } \\
\text { Take-up of outdoor activities is above average }\end{array}$ \\
\hline $\begin{array}{l}\text { John \& } \\
\text { Ann }\end{array}$ & $46-65$ & $11.6 \%$ & $\begin{array}{ll}\text { - } & \text { Married with grown up children who no longer live at } \\
& \text { home } \\
\text { - } & \text { Retired or are considering retirement } \\
\text { - } & \text { Have good careers and can afford a few luxuries } \\
\end{array}$ & $\begin{array}{l}\text { - Quite active with patterns of participation slightly } \\
\text { lower that national averages } \\
\text { - Keeping fit is the primary motivation } \\
\text { - Least likely to participate in team games }\end{array}$ \\
\hline
\end{tabular}

Table 1 Analysis of Five of Sport Wales' Market Segmentation Groups (adapted from Sports Council Wales, 2008) 